\title{
From inhaler to lung: clinical implications of the formulations of ciclesonide and other inhaled corticosteroids
}

This article was published in the following Dove Press journal:

International Journal of General Medicine

6 March 2013

Number of times this article has been viewed

\author{
Ruediger Nave \\ Helgert Mueller \\ Nycomed: a Takeda Company, \\ Nycomed GmbH, Konstanz, Germany
}

Correspondence: Helgert Mueller Nycomed: a Takeda Company, Nycomed GmbH, Byk-Gulden-Str 2, 78467 Konstanz, Germany

Tel +49753 I84 2693

Fax +49753 I8492693

Email helgert.mueller@takeda.com

\begin{abstract}
Asthma continues to be a global health problem and currently available treatments such as corticosteroids can cause unwanted side effects. Inhaled corticosteroids (ICS) are recommended as first-line therapy for reducing airway inflammation and have a distinct advantage over oral preparations as they provide a direct route of delivery to the lungs. However, local deposition of ICS in the oropharynx can lead to oral candidiasis, dysphonia, and pharyngitis. The pharmaceutical quality is a primary concern of any ICS asthma treatment, with a higher quality product resulting in improved efficacy and safety profiles. The particle size distribution and the spray force velocity of an ICS may directly influence lung deposition, and the spray duration of a device is another important factor when coordinating inhalation. Recent advances in ICS device and formulation technology have resulted in significant improvements in the efficacy of available asthma treatments. In particular, hydrofluoroalkane (HFA) solution technology and the development of smaller particle sizes have resulted in the production of new ICS formulations that have the ability to directly target drug delivery to the site of airway inflammation. Both the ICS formulation and the pressurized metered-dose inhaler device used to administer ciclesonide (CIC) HFA have been developed to treat the underlying chronic inflammation associated with asthma. CIC is administered as a prodrug which is activated in the lungs, leading to minimal oropharyngeal deposition. The small particle size of CIC results in the delivery of a high fraction of respirable particles to the small airways of the lungs, resulting in high lung deposition and continual dose consistency. This review summarizes how CIC administered as an HFA formulation is an effective treatment for asthma.
\end{abstract}

Keywords: ciclesonide, asthma, small airways, lung deposition

\section{Introduction}

Asthma is a chronic inflammatory disorder of the airways that continues to be a serious global health problem affecting an estimated 300 million people worldwide. ${ }^{1}$ Oral treatments (in particular oral steroids) act systemically and can cause unwanted side effects. Inhaled corticosteroids (ICS) are recommended as first-line therapy for reducing airway inflammation and have a distinct advantage over oral preparations because they provide a direct route of delivery to the lungs. ${ }^{2,3}$ However, their use may result in systemic side effects such as decreased bone mineral density, skin atrophy and bruising, cataracts, and impaired growth in children., ${ }^{3,4}$ The Global Initiative for Asthma guidelines recommend ICS treatment for all patients with persistent asthma regardless of severity. ${ }^{1}$

Several different types of inhaler are commercially available for the delivery of ICS. The pressurized metered-dose inhaler (pMDI) is a widely available device 
which uses hydrofluoroalkane (HFA) as a propellant. It requires coordination between actuation and inhalation when used without a spacer or a breath-activated inhaler. Dry-powder inhalers (DPIs) are an alternative type of device usually activated by inhalation. This removes the need for patients to master hand-breath coordination. ${ }^{5} \mathrm{~A}$ DPI requires energy from the inspiratory effort of the patient to disaggregate the powder into particles which are small enough to be inhaled. ${ }^{6}$

Understanding the clinical pharmacokinetic and pharmacodynamic properties of an ICS can be used to improve drug delivery as both directly impact efficacy and safety profiles of the ICS. ${ }^{7}$ Pharmaceutical quality is the primary concern of any ICS asthma treatment, with a higher quality product resulting in improved lung function and safety profiles. $^{2}$

As well as having a high-quality ICS formulation, there are a number of desirable properties of an inhaler device which may aid optimal drug delivery. It is essential that the device is robust and reliable and can work well over a broad range of temperatures, providing an accurate and uniform dose. Additionally, portability and ease of use are also important features to consider (Table 1).

The continual development of ICS formulations has resulted in significant advancements in aerosol therapy. This review explores the innovative formulation and pharmacological profile of one such ICS, ciclesonide (CIC), which is available as an HFA-MDI, and discusses in detail the properties of CIC; in particular, its small particle size allows the delivery of a high fraction of respirable particles to the small airways, resulting in relatively higher lung deposition and continual dose consistency when compared with other ICS.

Table I Desirable characteristics of an effective asthma ICS device

\begin{tabular}{ll}
\hline $\begin{array}{l}\text { Robustness } \\
\text { of the device }\end{array}$ & $\begin{array}{l}\text { Under standard-use scenarios the device works well } \\
\text { over a broad range of temperatures }\end{array}$ \\
Ease of use & $\begin{array}{l}\text { The device is ready to use without any prior preparation } \\
\text { such as shaking or priming when in constant use' } \\
\text { The device is small, portable and easy to handle by } \\
\text { all patients within the indication; children, elderly and } \\
\text { severely ill } \\
\text { Ideally the device will provide a formulation and } \\
\text { container-closure-system ensuring physical and } \\
\text { chemical stability over the shelf-life of the product }\end{array}$ \\
Stability of & $\begin{array}{l}\text { Low cost per dose to patient } \\
\text { formulation }\end{array}$ \\
Cost efficiency & $\begin{array}{l}\text { Accuracy and uniformity of each delivered dose is } \\
\text { Delivered dose }\end{array}$ \\
& times
\end{tabular}

Abbreviation: ICS, inhaled corticosteroids.

\section{Formulation and dose consistency}

The formulation of an ICS can directly affect the efficacy and safety of the drug. Ease of administration and accurate dose delivery are two highly desirable characteristics of any ICS formulation and delivery device. The following studies outline how CIC exhibits these qualities with regards to bioequivalence at different concentrations and consistent dose delivery over a range of temperatures.

Drug formulations used in MDIs are developed as either a solution or a suspension. A suspension pMDI is one in which the solid drug particles are suspended in a liquid propellant, and they therefore require shaking to ensure dose uniformity prior to inhalation. ${ }^{8}$ A solution pMDI does not require any shaking before use as the drug has been dissolved in the propellant/co-solvent formulation during manufacture, which may improve the ease of use for the patient and/or dose delivery of ICS solutions over suspensions.

One in vitro study compared the dose delivered from $\mathrm{CIC}$ and beclomethasone dipropionate (BDP) pMDIs (chlorofluorocarbon [CFC]-free] containing clear drug solutions, fluticasone propionate (FP) containing a CFC-free suspension, and budesonide (BUD) containing a suspension in a mixture of CFC propellants. The delivered dose of CIC, $\mathrm{BDP}$, and BUD remained constant over the lifespan of the pMDI, whereas the delivered dose of two FP dose strengths decreased. ${ }^{9}$ The consistency of delivered CIC doses has indirectly been demonstrated in a pharmacokinetic study investigating the bioequivalence of two CIC dose strengths: a total amount of $640 \mu \mathrm{g}$ was administered via pMDIs to healthy subjects as four puffs of $160 \mu \mathrm{g}$ or 16 puffs of $40 \mu \mathrm{g}$. Despite the use of 16 puffs within a few minutes, the rate and extent of absorption of the drug was very similar. ${ }^{10}$

In terms of robustness of the inhaler device, data show that the dose of CIC does not vary considerably with temperature (Table 2).

Table 2 Effect of temperature on fine particle dose of CIC I60 $\mathrm{gg}$ inhalers (Takeda batch \# 4BG009)

\begin{tabular}{lllll}
\hline Temperature & \multicolumn{5}{l}{ Fine particle dose* $(\mu \mathrm{g} /$ shot $)$} \\
\cline { 2 - 5 } & $\mathbf{4 0} \mathbf{C}$ & $\mathbf{2 5 ^ { \circ } \mathbf { C }}$ & $\mathbf{4}^{\circ} \mathbf{C}$ & $-10^{\circ} \mathbf{C}$ \\
\hline Mean & 102 & 101 & 100 & 103 \\
Range (min-max) & $90-119$ & $87-108$ & $82-107$ & $82-116$ \\
\hline
\end{tabular}

Notes: *Fine particle dose: total cumulative drug mass (ciclesonide) collected on the filter to stage 3 of the $\mathrm{ACl}$. The effect of a range of temperatures $\left(-10^{\circ} \mathrm{C}\right.$ to $\left.40^{\circ} \mathrm{C}\right)$ upon the fine particle dose was determined by $\mathrm{ACl}$ testing. The mass of $\mathrm{ClC}<5 \mu \mathrm{m}$ did not vary considerably in the temperature range examined. Nycomed: a Takeda company, data on file 2001.

Abbreviations: $\mathrm{ClC}$, ciclesonide; $\mathrm{ACl}$, Andersen cascade impactor. 


\section{Particle size and distribution}

ICS particle size plays an important role in aerosol therapy as it influences the extent, distribution, and site of inhaled drug deposition within the airways. In this section we review the beneficial effects of using ICS with smaller particle sizes, and discuss how particle size distribution (PSD) can directly affect the deposition of an ICS within the respiratory tract.

HFA solution technology has resulted in significant improvements in the delivery of ICS treatments, as the smaller particle size in HFA solution aerosols allows for a smaller spray orifice diameter. This reduces the primary aerosol droplet size of the device, resulting in the creation of smaller drug particles after evaporation of the propellant. ${ }^{8}$ These smaller drug particles can reach and reduce inflammation in the small airways of the lung. The small airways are defined as those that have an internal diameter of less than $2 \mathrm{~mm}$ and include the terminal bronchioles, respiratory bronchioles, alveolar ducts, and sacs. ${ }^{11}$ They have been described as a "quiet zone," primarily due to the perception that they have a limited contribution to total airway resistance of the bronchial tree. However, recent evidence indicates that this is not the case; inflammation in the small airways contributes significantly to asthma pathology. ${ }^{12,13}$ The small airways account for $98.8 \%$ (approximately $4500 \mathrm{~mL}$ ) of the total lung volume, whereas the lung volume of the large airways amounts to $50 \mathrm{~mL} .{ }^{14}$

There is substantial evidence of the involvement of small airways in the development of asthma symptoms. ${ }^{15}$ In order to treat asthma symptoms effectively, it is imperative that the ICS can reach the small airways. Understanding the role of the small airways in asthma symptoms has aided the development of novel asthma treatments and ways to optimize deposition in the lung periphery. This has led to the development of ICS treatments with smaller particles which directly target the site where asthma symptoms develop, thus improving drug delivery.

The introduction of HFA solution technology has led to the production of smaller optimal sized particles, with new drugs engineered to have an average particle size of $<2 \mu \mathrm{m}$ for $\mathrm{pMDI}$ inhalers. This has resulted in lung deposition values greater than $50 \%$, marking a turning point in the development of new ICS treatments. ${ }^{8}$

PSD is directly related to the mass of the therapeutically active pharmaceutical ingredient available in the lungs. Particle aerodynamic size, known as the mass median aerodynamic diameter (MMAD), which is the diameter at which $50 \%$ of particles by mass are larger and $50 \%$ are smaller, can reflect the distribution pattern and therefore the likely deposition location of the active component of a drug in the respiratory tract. ${ }^{16}$

An Andersen cascade impactor is a device used to determine the PSD of aerosols from pMDIs. Thus the aerodynamic characteristics (fine particle dose and MMAD) of a dose can provide in vitro data about its potential for deposition in the lungs.

Comparing different ICS formulations, it is clear that FP (delivered via a DPI) particles have the largest MMAD, ${ }^{12}$ followed by BUD (delivered via DPI), while CIC and BDP (delivered via HFA-MDI) have the smallest particles with an MMAD $<2 \mu \mathrm{m}$ (Figure 1). ${ }^{12}$ The relationship between particle size and penetration into the airways is presented in Table $3 .^{17}$ The PSD of CIC $160 \mu \mathrm{g}$ (batch number 4BGA001 as used by Newman et al) ${ }^{18}$ is presented in Figure 2. The highest proportion of particles of CIC ranged between 1.1 and $2.1 \mu \mathrm{m} .{ }^{18}$

De Vries et al compared the PSD of HFA-FP, BUD (a suspension of CFC propellants), HFA-BDP, and HFACIC using laser diffraction analysis. Lifespan, flow rate, and air humidity had no significant influence on PSD, and a significant difference in median PSD was observed between the four ICS pMDIs. De Vries et al concluded that CIC and BDP were the most suitable ICS for pediatric use due to their small particle size. ${ }^{9}$

\section{Maximizing lung deposition, minimizing oropharyngeal deposition}

An ideal ICS has minimal deposition in the oropharynx and maximal deposition in the lungs. A number of studies in vivo have provided direct evidence that ICS with smaller particle sizes such as CIC have greater lung deposition.

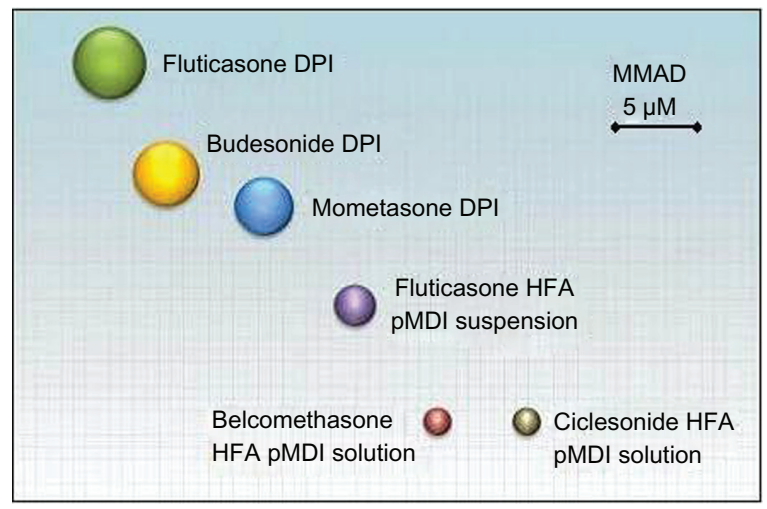

Figure I Comparison of the reported MMAD of inhaled corticosteroids for the treatment of asthma.

Note: Data from ${ }^{12,17,19-21,50}$

Abbreviations: DPI, dry powder inhaler; HFA, hydrofluoroalkane; MMAD, mass median aerodynamic diameters; pMDI, pressurized metered dose inhaler. 
Table 3 The relationship between particle size and particle penetration into the airways and stages of the Andersen cascade impactor (operated at $28 \mathrm{~L} /$ minute)

\begin{tabular}{lll}
\hline Stage & Particle size $(\mu \mathrm{m})$ & Deposition in respiratory tract \\
\hline 0 & $9.00-10.00$ & \\
1 & $5.80-9.00$ & \\
2 & $4.70-5.80$ & Pharynx \\
3 & $3.30-4.70$ & Trachea and primary bronchi \\
4 & $2.10-3.30$ & Secondary bronchi \\
5 & $1.10-2.10$ & Terminal bronchi \\
6 & $0.65-1.10$ & Alveoli \\
7 & $0.43-0.65$ & Alveoli \\
Filter & $<0.43$ & \\
\hline
\end{tabular}

Copyright (c) 2000, WB Saunders Co, Ltd. Reproduced with permission from Cripps A, Riebe M, Schulze M, Woodhouse R. Pharmaceutical transition to non-CFC pressurized metered dose inhalers. Respir Med. 2000;94(Suppl B):S3-S9.17

Lung deposition and peripheral distribution can vary considerably between DPIs and pMDIs. ${ }^{22,23}$ To investigate in vivo pulmonary deposition, radiolabelled formulations can be used with $2 \mathrm{D}$ and $3 \mathrm{D}$ imaging techniques. In a randomized study in patients with asthma, the deposition of inhaled technetium-99m-labelled monodisperse albuterol of 1.5, 3, and $6 \mu \mathrm{m}$ MMAD was assessed. ${ }^{22}$ The smaller particles achieved greater total lung deposition than the larger particles $(1.5 \mu \mathrm{m}$ [56\%], $3 \mu \mathrm{m}[50 \%]$, and $6 \mu \mathrm{m} \mathrm{[46 \% ])} \mathrm{(Figure} \mathrm{3).} \mathrm{Oropharyngeal} \mathrm{deposition} \mathrm{was}$ highest for particles of $3 \mu \mathrm{m}$ and $6 \mu \mathrm{m}$, which were more prone to inertial impaction due to their relatively larger size. ${ }^{22}$ Similarly in a study using healthy subjects, the lung deposition of radiolabelled HFA-BDP was compared with CFC-FP and CFC-BDP; deposition values were related to the PSD of each ICS, with the smaller particles of HFA-BDP providing the greatest lung deposition and the least oropharyngeal deposition. ${ }^{24}$

In two studies that investigated lung and oropharyngeal deposition of technetium-99m-labelled CIC inhaled via an HFA-MDI, both 2D and 3D imaging showed a high lung deposition (52\%), with greater distribution throughout the peripheral regions of the lung compared with oropharyngeal deposition (32.9\%). ${ }^{21}$ Newman et al observed during an analysis of the distribution of ${ }^{99 \mathrm{~m}} \mathrm{Tc}-\mathrm{CIC} 160 \mu \mathrm{g}$ in each of the six 'shells' of the right lung that $>29 \%$ of the deposited dose reached the outermost peripheral region. ${ }^{18}$

Local deposition of ICS in the oropharynx may cause side effects such as oral candidiasis, dysphonia, and pharyngitis, ${ }^{25}$ and so should be minimized. The small proportion of CIC deposited in the oropharynx and its administration as an inactive prodrug contribute to the reduced incidence of localized side effects. After inhalation, the inactive CIC is converted by esterases in the airways to the active metabolite desisobutyryl-CIC (des-CIC), ${ }^{26,27}$ an approach which restricts the anti-inflammatory activity of CIC to the desired site of action. Activation of CIC has been confirmed in vivo by Nave et al in a lung deposition study, in patients undergoing elective lung surgery for malignant pulmonary lesions. After inhalation of one dose of $\mathrm{CIC}$ at various time points prior to undergoing lung tissue resection, the pharmacologically active des-CIC was detected in the resected central and peripheral lung tissues. ${ }^{28}$

Investigations into the oropharyngeal deposition of ICS using mouth-rinsing studies have shown that the oropharyngeal deposition of CIC is lower compared with that of FP and BUD. ${ }^{29,30}$ Additionally, little activation of CIC to its active

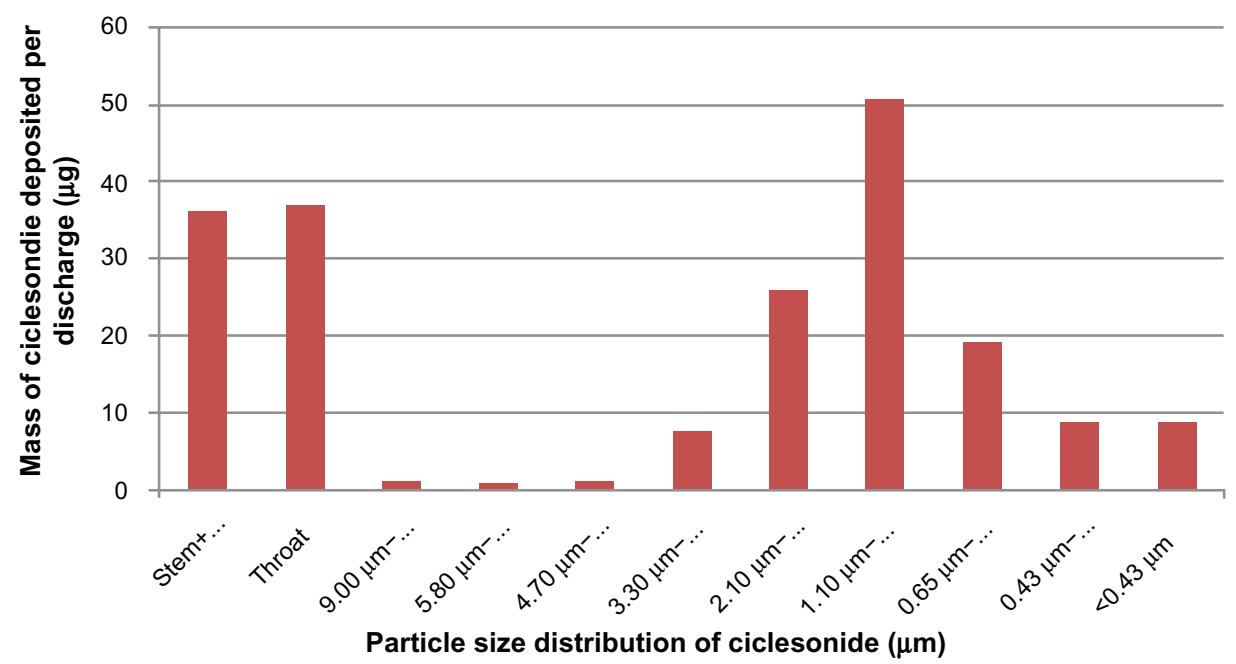

Figure 2 Aerodynamic particle size distribution of CIC pMDI, Batch No 4BGA00I (MMAD = I.52 $\mu \mathrm{m}$, fine particle dose $=12 \mathrm{I} \mu \mathrm{g}$ ) (Nycomed: a Takeda company, data on file 200I). Abbreviations: $\mathrm{CIC}$, ciclesonide; MMAD, mass median aerodynamic diameters; pMDI, pressurized metered dose inhaler. 

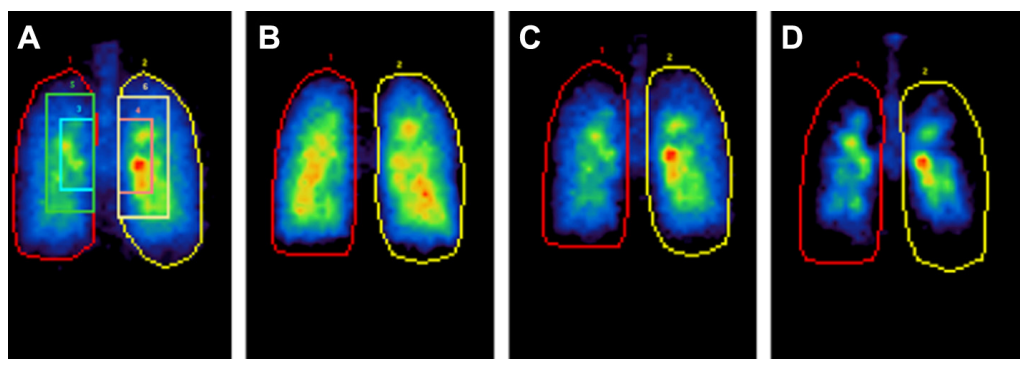

Figure 3 Regional lung deposition of inhaled technetium-99m-labeled monodisperse albuterol aerosols. (A) $5 \times 8$ matrix was closely fitted to the krypton ventilation-scan lung boundary and superimposed on the posterior thorax aerosol deposition images, which was partitioned into a central zone, $2 \times 3$ matrix centered on the lung hilum; an intermediate zone, $3 \times 5$ matrix excluding the central zone; and a peripheral zone defined as the remaining lung field within the lung outline. (B) $1.5 \mu \mathrm{m}$, (C) $3 \mu \mathrm{m}$, and (D) $6 \mu \mathrm{m}$ MMAD. Note: Red areas indicate regions of highest radioactivity, and black of least radioactivity.

Reprinted with permission of the American Thoracic Society. Copyright (c) 2005 American Thoracic Society. Usmani OS, Biddiscombe MF, Barnes PJ. Regional lung deposition and bronchodilator response as a function of beta2-agonist particle size. Am J Respir Crit Care Med. 2005; 172(12):1497-1504. ${ }^{22}$ Official journal of the American Thoracic Society.

Abbreviation: MMAD, mass median aerodynamic diameters.

metabolite des-CIC occurs in the oropharynx, suggesting a lower likelihood of CIC-associated oropharyngeal side effects. ${ }^{18,29,30}$

\section{Improvement of small airway function using ICS}

When ICS are administered in HFA-MDI solution formulations, a number of clinical benefits such as a reduction in small airway inflammation have been observed. This section identifies several studies that highlight the potential benefits of using CIC to improve small airway function.

In a randomized study with asthma patients, Thongngarm et al compared the efficacy of CFC-FP (a suspension) and HFA-BDP (a solution) and found that HFA-BDP had a greater effect on reducing small airway inflammation due to its smaller particle size. ${ }^{31}$

A comparative study by Hoshino et al showed that CIC could improve small airway function and inflammation in patients with mild asthma. After pre-treatment with a largeparticle FP DPI for 8 weeks, patients were randomized to receive either HFA-pMDI-CIC or FP-DPI and their small airway function assessed by impulse oscillometry and the percentage of eosinophils in induced sputum. When compared with baseline, HFA-pMDI-CIC was found to significantly improve resistance in the small airways, distal reactance, and reactance area, and also decreased late-phase sputum eosinophil level $(P<0.01)$; in contrast, FP-DPI did not significantly improve small airway function, and asthma control (compared using the Asthma Control Test [ACT]) improved in patients who received CIC but not with FP. ${ }^{32}$ These data collectively indicate that CIC may exhibit high lung deposition, small airway distribution, and minimal deposition in the oropharynx, which is largely due to its small particle size. . $1,21,29,30^{2}$

\section{Systemic availability of ICS in healthy subjects and asthma patients}

Systemically, ICS can be delivered via the pulmonary or oral routes. There are numerous clinical safety aspects to consider when using ICS in aerosols designed to treat asthma, and the potential for long-term side effects from ICS relates to systemic absorption. ${ }^{33}$

Extra-fine particles (smaller than $0.65 \mu \mathrm{m}$ ) may reach the systemic circulation and therefore achieve high maximum plasma concentration values $\left(\mathrm{C}_{\max }\right)$. CIC is a prodrug and so ideally $\mathrm{C}_{\max }$ values of des-CIC (rather than CIC) should be compared. Nave et al compared the pharmacokinetics of des$\mathrm{CIC}$ to BUD, and observed that much higher $\mathrm{C}_{\max }$ values were achieved with BUD than des-CIC. ${ }^{34}$ The pharmacokinetics of CIC and its active metabolite, des-CIC, indicate that the drug has negligible oral bioavailability, and the pulmonary bioavailability of des-CIC has been found to be more than $60 \%{ }^{2,41}$ Several studies have shown that the resulting systemic exposure after treatment with some ICS is different in asthma patients when compared with healthy subjects. ${ }^{35}$ Systemic availability of FP is substantially less in patients with moderate-to-severe asthma when compared with healthy subjects, suggesting lower lung deposition and indicating that concentrations of ICS should not be assessed in healthy subjects, but in patients receiving doses appropriate for their disease severity. ${ }^{36}$

Harrison et al also found greater systemic availability of FP in healthy subjects when compared with asthmatic subjects. FP was found to have a greater effect on the hypothalamic-pituitary-adrenal axis in healthy subjects than in subjects with asthma, but this was not true for BUD $1600 \mu \mathrm{g} /$ day ${ }^{33}$ Interestingly, Nave et al showed that when 
a group of healthy subjects and asthma patients were given CIC, the pharmacokinetic parameter estimates for des-CIC were equivalent between the two groups, suggesting comparable lung deposition and activation of CIC in both healthy and mild-to-moderate asthmatic subjects. They concluded that there was no effect of asthma on the pharmacokinetic properties of $\mathrm{CIC}{ }^{37}$

ICS deposited in the oropharynx will be swallowed and may enter the systemic circulation depending on the oral bioavailability of the drug. The extent of oral absorption and bioavailability of CIC referenced to an intravenous infusion was investigated using radiolabelled CIC. It was observed that CIC was undetectable in serum after oral administration of a high dose (6.9 mg CIC) and that the systemic bioavailability for des-CIC was $<1 \% .{ }^{38}$ These results show that any CIC swallowed after oral inhalation does not contribute to the systemic availability. For other ICS like BUD and BDP, oral bioavailabilities of $11 \%$ and up to $41 \%$ for B-17-MP are reported, respectively. ${ }^{39,40}$ Therefore for some ICS the oral bioavailability has to be considered, as the swallowed drug will enter the systemic circulation without being effective in the lung.

\section{Spray force, plume velocity and dose}

Spray force and plume velocity are important aerosol characteristics that can influence lung deposition of an ICS. The time period over which the aerosol is released (spray duration) is another important factor to be considered when coordinating inhalation. ${ }^{42}$ The type of propellant used can affect spray force with CFC-containing pMDIs producing extremely forceful and cold plumes. Comparatively, several HFA-containing solution pMDIs produce much softer and warmer plumes. ${ }^{43}$ Another factor that affects spray force is the actuator orifice diameter. Data obtained from marketed products and experimental inhalers show that pMDIs that have a low spray force also have low throat deposition (Figure 3). ${ }^{43}$ HFA propellants have been observed to have a much lower spray force velocity than for CFC aerosols. In a study in healthy subjects which compared the lung deposition of HFA-134a BDP with CFC-FP, HFA-BDP was found to be emitted at a much lower spray force (approximately $35 \mathrm{mN}$ ) when compared with CFC-FP or HFA-FP and CFC-BDP (100 to $120 \mathrm{mN}){ }^{24}$

Spray plumes can vary considerably between HFA inhalers. The spray plumes emitted from a CIC HFA-solution pMDI and FP administered as an HFA-suspension pMDA are visually compared in Figure 4. A relatively low spray

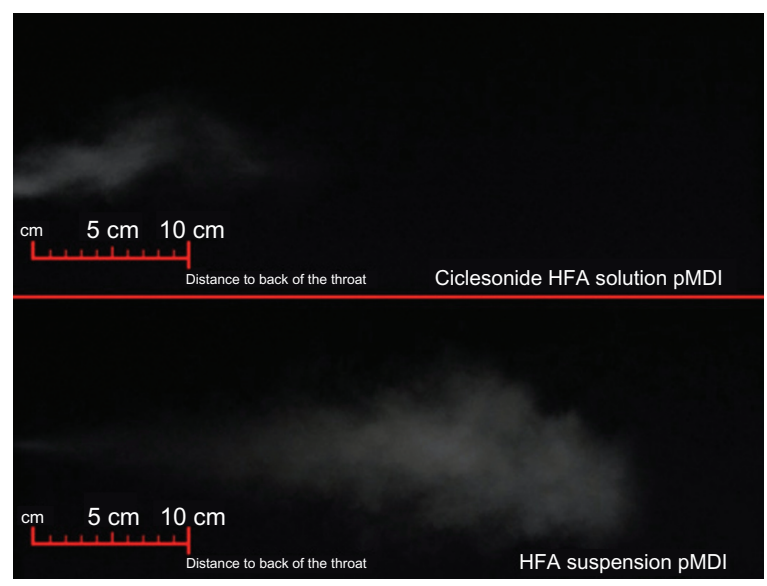

Figure 4 Visual comparison of the spray plumes emitted from a CIC HFA-solution PMDI and FP administered as an HFA-suspension pMDI.

Note: Nycomed: a Takeda company, data on file, 2012.

Abbreviations: $\mathrm{ClC}$, ciclesonide; FP, fluticasone propionate; HFA, hydrofluoroalkane; pMDI, pressurized metered dose inhaler.

velocity can reduce inertial impaction in the oropharynx. The ex-actuator velocity profile of the spray plume has been calculated at various time points using high-speed photography to capture the image of the plume as a function of time (Figure 4). For HFA-CIC the initial mean plume velocity was approximately $9 \mathrm{~m} / \mathrm{second}$ at a distance of $30 \mathrm{~mm}$ from the MDI mouthpiece which was reduced to around $6 \mathrm{~m} / \mathrm{second}$ at a $50 \mathrm{~mm}$ distance point.

\section{Optimizing the use of inhaler devices}

When considering the spray properties of an ICS inhaler device, factors such as the PSD, volume, speed, and concentration of the spray directly affect the amount of ICS that reaches the small airways on inhalation. Ideally, each actuation results in a dose that is uniform in terms of concentration and volume. As well as the design of the formulation of the ICS, the correct use of these devices can have a major influence on their overall effectiveness, in that poor inhaler technique can result in a reduced amount of drug being absorbed into the lung and can therefore negatively impact drug efficacy.

The required inhaler technique is dependent on the type of device used. Good technique with pMDIs requires inhalation from the functional residual capacity or residual volume timed to coincide with the device actuation, at a reasonably slow and steady inspiratory flow rate. A breath-hold of 5-10 seconds after inhalation may increase drug deposition but may not be essential for efficacy. ${ }^{44}$ In order to produce optimal results when using pMDIs, patient education is required and it is imperative that patients are educated on correct pMDI handling for optimum results. ${ }^{45}$ Importantly the patient's ability to 
prepare and actuate a device should be assessed; in particular, the patient should be observed to see whether they are able to take an adequate inspiration and coordinate actuation of a pMDI with inspiration.

DPIs are flow-dependent devices, and coordination between inhalation and actuation is not required. However, there is still the potential for this type of inhaler to be used incorrectly. Some of the most common errors made when using DPIs include failure to exhale before actuation, and incorrect positioning of the inhaler. Some patients (the elderly or those with severe asthma) may be unable to execute a forceful and deep inhalation, resulting in failure to properly activate these devices. ${ }^{45}$

The use of spacer devices has been implemented to help patients using pMDIs. Patients with poor inhaler technique (particularly children or the elderly) can use spacer devices in combination with the pMDI which help to reduce difficulties with actuation-inhalation. However, Drollmann et al observed that the pharmacokinetic properties of the active metabolite des-CIC were comparable after inhalation with and without an AeroChamber Plus ${ }^{\circledR}$ (Trudell Medical International, London, Ontario, Canada) spacer, ${ }^{46}$ suggesting that CIC-HFA pMDI does not require a spacer for optimal delivery. The results from a pediatric study that enrolled children (aged 6-11 years) indicated that the use of a spacer resulted in a slight increase in the systemic exposure of des-CIC and also showed that inhaled CIC ( $80 \mu \mathrm{g}$ and $160 \mu \mathrm{g})$ with spacer led to dose proportional systemic exposure. ${ }^{47}$ There is some evidence which suggests the use of a spacer device enhances pMDI therapy by reducing the amount of drug deposited in the oropharyngeal region, leading to fewer instances of local and systemic side effects. In addition, spacer devices allow a higher dose of drug to reach the deep lung, which may permit the use of lower dosage regimens with increased therapeutic efficacy. ${ }^{48}$ In the pediatric RAINBOW study, ${ }^{49}$ children (aged 6-11 years) with persistent asthma were randomized to receive either placebo or CIC at $40 \mu \mathrm{g}, 80 \mu \mathrm{g}$, or $160 \mu \mathrm{g}$ once daily. All doses were found to be equally effective, and the efficacy and safety of CIC were unaffected by the use of a spacer. It was also noted that cortisol levels were comparable between all treatment groups. ${ }^{49}$

\section{Summary}

Due to the prevalence of asthma, there has been a requirement for a novel, high-quality asthma treatment that is robust, easy to use, chemically and physically stable, cost efficient, and has the ability to consistently deliver an accurate dose that can directly target inflammation in the small airways.
The use of HFA in ICS formulations was the first step in the development of such asthma treatments, allowing smaller particles to be used in the ICS formulations which could reach the small airways.

There is a large quantity of evidence that supports HFA-CIC pMDI as a high-quality product, since both the ICS formulation and inhaler device have been designed as an effective asthma treatment. In particular, CIC is an ICS administered as a prodrug and is activated in the respiratory tract. High protein-binding lowers the systemic level of the pharmacologically active metabolite des-CIC, minimizing the potential for systemic side effects by reducing the amount of freely circulating protein-unbound des-CIC in the systemic circulation. $^{26}$

\section{Acknowledgments}

Editorial assistance in preparation of this manuscript was provided by Caroline Loder of Synergy Vision, London, UK and funded by Nycomed: a Takeda Company, Nycomed $\mathrm{GmbH}$, Konstanz, Germany, who have developed CIC as a product.

\section{Disclosure}

The authors are employees of Nycomed: a Takeda Company, Nycomed GmbH, Konstanz, Germany.

\section{References}

1. GINA [webpage on the Internet]. From the Global Strategy for Asthma Management and Prevention. Global Initiative for Asthma (GINA); 2012. Available from: http://www.ginasthma.org/guidelines-gina-reportglobal-strategy-for-asthma.html. Accessed January 18, 2013.

2. Nave R. Clinical pharmacokinetic and pharmacodynamic profile of inhaled ciclesonide. Clin Pharmacokinet. 2009;48(4):243-252.

3. Allen DB, Bielory L, Derendorf H, Dluhy R, Colice GL, Szefler SJ. Inhaled corticosteroids: past lessons and future issues. J Allergy Clin Immunol. 2003;112(Suppl 3):S1-S40.

4. Dahl R. Systemic side effects of inhaled corticosteroids in patients with asthma. Respir Med. 2006;100(8):1307-1317.

5. Berger W. Aerosol devices and asthma therapy. Curr Drug Deliv. 2009;6(1):38-49.

6. Everard ML, Devadason SG, Le Souëf PN. Flow early in the inspiratory manoeuvre affects the aerosol particle size distribution from a Turbuhaler. Respir Med. 1997;91(10):624-628.

7. Rohatagi S, Appajosyula S, Derendorf H, et al. Risk-benefit value of inhaled glucocorticoids: a pharmacokinetic/pharmacodynamic perspective. J Clin Pharmacol. 2004;44(1):37-47.

8. Leach C, Colice GL, Luskin A. Particle size of inhaled corticosteroids: does it matter? J Allergy Clin Immunol. 2009;124(Suppl 6):S88-S93.

9. de Vries TW, Rottier BL, Gjaltema D, Hagedoorn P, Frijlink HW, de Boer AH. Comparative in vitro evaluation of four corticosteroid metered dose inhalers: consistency of delivered dose and particle size distribution. Respir Med. 2009;103(8):1167-1173.

10. Bethke TD, Drollman A, Hauns B, et al. Bioequivalence of two ciclesonide dosing regimen (4 puffs of $200 \mu \mathrm{g}$ versus 16 puffs of $50 \mu \mathrm{g}$ using a MDI). Eur Respir J.2002;20(Suppl 38):109s.

11. Weibel ER. Principles and methods for the morphometric study of the lung and other organs. Lab Invest. 1963;12:131-155. 
12. Martin RJ. Therapeutic significance of distal airway inflammation in asthma. J Allergy Clin Immunol. 2002;109(Suppl 2):S447-S460.

13. Contoli M, Bousquet J, Fabbri LM, et al. The small airways and distal lung compartment in asthma and COPD: a time for reappraisal. Allergy. 2010;65(2):141-151.

14. Virchow JC. Asthma - a small airway disease: concepts and evidence. Pneumologie. 2009;63(Suppl 2):S96-S101.

15. Tulic MK, Hamid Q. Contribution of the distal lung to the pathologic and physiologic changes in asthma: potential therapeutic target Roger S. Mitchell lecture. Chest. 2003;123(Suppl 3):348S-355S.

16. Mitchell JP, Nagel MW, Wiersema KJ, Doyle CC. Aerodynamic particle size analysis of aerosols from pressurized metered-dose inhalers: comparison of Andersen 8-stage cascade impactor, next generation pharmaceutical impactor, and model 3321 Aerodynamic Particle Sizer aerosol spectrometer. AAPS Pharm Sci Tech. 2003;4(4):E54.

17. Cripps A, Riebe M, Schulze M, Woodhouse R. Pharmaceutical transition to non-CFC pressurized metered dose inhalers. Respir Med. 2000;94(Suppl B):S3-S9.

18. Newman S, Salmon A, Nave R, Drollmann A. High lung deposition of $99 \mathrm{mTc}$-labeled ciclesonide administered via HFA-MDI to patients with asthma. Respir Med. 2006;100(3):375-384.

19. Yang TT, Li S, Wyka B, Kenyon D. Drug delivery performance of the mometasone furoate dry powder inhaler. J Aerosol Med. 2001;14(4):487-494.

20. Leach CL, Davidson PJ, Boudreau RJ. Improved airway targeting with the CFC-free HFA-beclomethasone metered-dose inhaler compared with CFC-beclomethasone. Eur Respir J. 1998;12(6):1346-1353.

21. Leach CL, Bethke TD, Boudreau RJ, et al. Two-dimensional and threedimensional imaging show ciclesonide has high lung deposition and peripheral distribution: a nonrandomized study in healthy volunteers. J Aerosol Med. 2006;19(2):117-126.

22. Usmani OS, Biddiscombe MF, Barnes PJ. Regional lung deposition and bronchodilator response as a function of beta2-agonist particle size. $\mathrm{Am}$ J Respir Crit Care Med. 2005;172(12):1497-1504.

23. Hirst PH, Bacon RE, Pitcairn GR, Silvasti M, Newman SP. A comparison of the lung deposition of budesonide from Easyhaler, Turbuhaler and pMDI plus spacer in asthmatic patients. Respir Med. 2001;95(9): $720-727$.

24. Leach CL, Davidson PJ, Hasselquist BE, Boudreau RJ. Lung deposition of hydrofluoroalkane-134a beclomethasone is greater than that of chlorofluorocarbon fluticasone and chlorofluorocarbon beclomethasone: a cross-over study in healthy volunteers. Chest. 2002;122(2):510-516.

25. Buhl R. Local oropharyngeal side effects of inhaled corticosteroids in patients with asthma. Allergy. 2006;61(5):518-526.

26. Mutch E, Nave R, McCracken N, Zech K, Williams FM. The role of esterases in the metabolism of ciclesonide to desisobutyryl-ciclesonide in human tissue. Biochem Pharmacol. 2007;73(10):1657-1664.

27. Nave R, McCracken N. Metabolism of ciclesonide in the upper and lower airways: review of available data. J Asthma Allergy. 2008;1:11-18.

28. Nave R, Watz H, Hoffmann H, Boss H, Magnussen H. Deposition and metabolism of inhaled ciclesonide in the human lung. Eur Respir J. 2010;36(5):1113-1119.

29. Richter K, Kanniess F, Biberger C, Nave R, Magnussen H. Comparison of the oropharyngeal deposition of inhaled ciclesonide and fluticasone propionate in patients with asthma. J Clin Pharmacol. 2005;45(2): $146-152$.

30. Nave R, Zech K, Bethke TD. Lower oropharyngeal deposition of inhaled ciclesonide via hydrofluoroalkane metered-dose inhaler compared with budesonide via chlorofluorocarbon metered-dose inhaler in healthy subjects. Eur J Clin Pharmacol. 2005;61(3):203-208.

31. Thongngarm T, Silkoff PE, Kossack WS, Nelson HS. Hydrofluoroalkane134A beclomethasone or chlorofluorocarbon fluticasone: effect on small airways in poorly controlled asthma. J Asthma. 2005;42(4): $257-263$.
32. Hoshino M. Comparison of effectiveness in ciclesonide and fluticasone propionate on small airway function in mild asthma. Allergol Int. 2010;59(1):59-66.

33. Harrison TW, Wisniewski A, Honour J, Tattersfield AE. Comparison of the systemic effects of fluticasone propionate and budesonide given by dry powder inhaler in healthy and asthmatic subjects. Thorax. 2001;56(3):186-191.

34. Nave R, Zech K, Bliesath H, Bethke T. Differences between pharmacokinetics of ciclesonide-active principle and budesonide following repeated dose inhalations. Eur Respir J. 2003;22:S45.

35. Rohatagi S, Luo Y, Shen L, et al. Protein binding and its potential for eliciting minimal systemic side effects with a novel inhaled corticosteroid, ciclesonide. Am J Ther. 2005;12(3):201-209.

36. Brutsche MH, Brutsche IC, Munawar M, et al. Comparison of pharmacokinetics and systemic effects of inhaled fluticasone propionate in patients with asthma and healthy volunteers: a randomised crossover study. Lancet. 2000;356(9229):556-561.

37. Nave R, Gunawardena KA, Zech K, Bethke TD. Pharmacokinetic disposition of inhaled ciclesonide and its metabolite desisobutyrylciclesonide in healthy subjects and patients with asthma are similar. Int J Clin Pharmacol Ther. 2006;44(1):1-7.

38. Nave R, Bethke TD, van Marle SP, Zech K. Pharmacokinetics of [14C] ciclesonide after oral and intravenous administration to healthy subjects. Clin Pharmacokinet. 2004;43(7):479-486.

39. Rohatagi S, Appajosyula S, Derendorf H, et al. Risk-benefit value of inhaled glucocorticoids: a pharmacokinetic/pharmacodynamic perspective. J Clin Pharmacol. 2004;44(1):37-47.

40. Daley-Yates PT, Price AC, Sisson JR, Pereira A, Dallow N. Beclomethasone dipropionate: absolute bioavailability, pharmacokinetics and metabolism following intravenous, oral, intranasal and inhaled administration in man. Br J Clin Pharmacol. 2001;51(5):400-409.

41. Nave R. Determination of lung deposition following inhalation of ciclesonide using different bioanalytical procedures. Bioanalysis. 2010;2(4):807-814.

42. Hochrainer D, Hölz H, Kreher C, Scaffidi L, Spallek M, Wachtel H. Comparison of the aerosol velocity and spray duration of Respimat Soft Mist inhaler and pressurized metered dose inhalers. J Aerosol Med. 2005; 18(3):273-282.

43. Gabrio BJ, Stein SW, Velasquez DJ. A new method to evaluate plume characteristics of hydrofluoroalkane and chlorofluorocarbon metered dose inhalers. Int J Pharm. 1999;186(1):3-12.

44. Chapman KR, Voshaar TH, Virchow JC. Inhaler choice in primary practice. Eur Respir Rev. 2011;14(96):117-122.

45. Khassawneh BY, Al-Ali MK, Alzoubi KH, et al. Handling of inhaler devices in actual pulmonary practice: metered-dose inhaler versus dry powder inhalers. Respir Care. 2008;53(3):324-328.

46. Drollmann A, Nave R, Steinijans VW, Baumgärtner E, Bethke TD. Equivalent pharmacokinetics of the active metabolite of ciclesonide with and without use of the AeroChamber Plus spacer for inhalation. Clin Pharmacokinet. 2006;45(7):729-736.

47. Boss H, Minic P, Nave R. Similar results in children with asthma for steady state pharmockinetic parameters of ciclesonide inhaled with or without spacer. Clinical Medicine Insights: Pediatrics. 2010;4: $1-10$.

48. Williams RO 3rd, Patel AM, Barron MK, Rogers TL. Investigation of some commercially available spacer devices for the delivery of glucocorticoid steroids from a pMDI. Drug Dev Ind Pharm. 2001;27(5): 401-412.

49. Pedersen S, Potter P, Dachev S, et al. Efficacy and safety of three ciclesonide doses vs placebo in children with asthma: the RAINBOW study. Respir Med. 2010;104(11):1618-1628.

50. van den Berge M, Ten Hacken NHT, van der Wiel E, Postma DS. Treatment of the bronchial tree from beginning to end: Targeting small airways inflammation in asthma. Allergy. 2013;68(1):16-26. 
International Journal of General Medicine

Dovepress

\section{Publish your work in this journal}

The International Journal of General Medicine is an international, peer-reviewed open-access journal that focuses on general and internal medicine, pathogenesis, epidemiology, diagnosis, monitoring and treatment protocols. The journal is characterized by the rapid reporting of reviews, original research and clinical studies across all disease areas.
A key focus is the elucidation of disease processes and management protocols resulting in improved outcomes for the patient. The manuscript management system is completely online and includes a very quick and fair peer-review system. Visit http://www.dovepress.com/ testimonials.php to read real quotes from published authors.

Submit your manuscript here: http://www.dovepress.com/international-journal-of-general-medicine-journal 